\title{
Do conceito de Atividade Orientadora de Ensino às situações desencadeadoras de aprendizagem em pesquisas sobre ensino e formação de professores
}

\author{
Flávia Dias de Souza \\ Claudiovane Parralego de Aguiar ${ }^{2}$ \\ Divanete Maria Bitdinger de Oliveira ${ }^{3}$ \\ Mariana Laís Batista 4
}

\begin{abstract}
RESUMO
$\mathrm{O}$ artigo tem como objetivo investigar como as situações desencadeadoras de aprendizagem podem ser elaboradas na direção da apropriação de um conceito matemático. O estudo centra-se no conceito de Atividade Orientadora de Ensino (AOE) como base teórico-metodológica para a organização do ensino e nas situações desencadeadoras de aprendizagem (SDA), desenvolvidas intencionalmente por meio de jogos, histórias virtuais e situações emergentes do cotidiano em pesquisas vinculadas ao Grupo de estudos e pesquisas sobre a Atividade Pedagógica. O caminho metodológico parte do levantamento de cinquenta pesquisas que envolvem o conceito de $\mathrm{AOE}$ e a formação de professores ou o ensino de matemática, em trabalhos vinculados aos pesquisadores do grupo ou de seus orientandos diretos, localizados a partir dos registros dos currículos Lattes. A análise das SDA nas pesquisas revela indícios do modo geral de organização do ensino e da formação que preservam princípios da AOE como a essência do conceito e a coletividade.
\end{abstract}

PALAVRAS-CHAVE: Atividade Orientadora de Ensino. Situações Desencadeadoras de Aprendizagem. Formação de Professores. Educação Matemática.

\footnotetext{
1 Doutora em Educação. Universidade Tecnológica Federal do Paraná, Curitiba, Paraná, Brasil. Orcid: https://orcid.org/0000-0002-0586-433X.E-mail: flaviad@utfpr.edu.br.

${ }^{2}$ Mestre em Educação Matemática. Universidade Tecnológica Federal do Paraná, Curitiba, Paraná, Brasil. Orcid: https://orcid.org/0000-0002-2188-5405.E-mail: clauparralego@hotmail.com.

${ }^{3}$ Mestre em Métodos Numéricos em Engenharia. Universidade Tecnológica Federal do Paraná, Curitiba, Paraná, Brasil. Orcid: https://orcid.org/0000-0002-8532-8990.E-mail: divanetem@utfpr.edu.br.

${ }^{4}$ Mestranda em Formação Científica, Educacional e Tecnológica. Universidade Tecnológica Federal do Paraná, Curitiba, Paraná, Brasil. Orcid: https://orcid.org/0000-0002-3985-9985. E-mail: marianalaisbatista@hotmail.com.
} 
From the concept of education-orienting activity to the situations that prompt learning in researches about teaching and teacher formation

\begin{abstract}
The article aims to investigate how situations that prompt learning can be elaborated in the direction of the appropriation of a mathematical concept. To attend to this objective, the study centers itself in the concept of the Education_Orienting Activity (AOE, translated) as the theoreticmethodological basis for teaching and in the concept of situations that prompt learning (SDA, translated), intentionally developed by the way of games, virtual stories and emerging situations in researches linked to the Study and Research on the Pedagogical Activity Group. The methodological path starts from the gathering of fifty researches which involve the concept of $\mathrm{AOE}$ and the formation of teachers or the teaching of Math in works related to the researchers of the group or to their direct post-graduate student, localized by their records in their Lattes curriculum. The analysis of the SDAs reveal signs of the general way of teaching organization and formation that preserves the principles of the AOE as the essence of the concept and collectivity.
\end{abstract}

KEYWORDS: Education-orienting activity. Situations that prompt learning. Teacher Formation. Mathematical Education.

Del concepto de actividad orientadora de la enseñanza a situaciones que desencadenan aprendizajes en la investigación sobre la docencia y la formación del profesorado

\title{
RESUMEN
}

El artículo tiene como objetivo investigar cómo se pueden elaborar las situaciones desencadenantes de aprendizaje en la dirección de la apropiación de un concepto matemático. El estudio se centra en el concepto de Actividad Orientadora de la Enseñanza (AOE) como base teórica y metodológica de la enseñanza y en el concepto de situaciones desencadenantes de aprendizaje (SDA), desarrolladas intencionalmente en el uso de juegos, historias virtuales y situaciones que emergen del cotidiano en la investigación vinculada al Grupo de Estudio e Investigación de la Actividad Pedagógica. El enfoque metodológico se basa en una 
encuesta de cincuenta estudios que involucran el concepto de AOE y la formación del profesorado o la enseñanza de las matemáticas, en trabajos vinculados a los investigadores del grupo o sus estudiantes de posgrado directos, ubicados a partir de los registros de los currículos 'Lattes'. El análisis de la SDA en la investigación revela evidencias de la forma general de organizar la educación y la formación que preserva los principios de la AOE como esencia del concepto y de la colectividad.

PALABRAS CLAVE: Actividad Orientadora de la Enseñanza. Situaciones desencadenantes de aprendizaje. Formación de profesores. Educación Matemática.

\section{Introdução}

A compreensão sobre os processos de ensino e aprendizagem e os modos de organização em que se dá a atividade pedagógica tem sido, desde a origem, objeto de estudo e investigação do Grupo de Estudos e Pesquisas sobre a Atividade Pedagógica (GEPAPe) ${ }^{5}$. Nesses estudos, a Teoria Histórico-Cultural, a Teoria da Atividade e, mais especificamente, o conceito de Atividade Orientadora de Ensino - AOE (MOURA, 1996, 2016), figuram como fundamentos teóricos e metodológicos para desenvolver as investigações realizadas e em curso nas pesquisas sobre educação e formação de professores, no âmbito do grupo.

A medida em que as pesquisas envolvendo o conceito de Atividade Orientadora de Ensino foram sendo desenvolvidas em programas de mestrado e doutorado, bem como em projetos de ensino e de extensão que envolvem integrantes do grupo, a necessidade de aprofundar a compreensão desse conceito foi se revelando propulsora de novos estudos.

Nessa direção, o presente estudo centra-se na Atividade Orientadora de Ensino como base teórico-metodológica para a organização do ensino e

\footnotetext{
${ }^{5}$ Grupo de Pesquisa vinculado à Faculdade de Educação da Universidade de São Paulo (FEUSP), criado no ano de 2002 e coordenado pelo Prof. Dr. Manoel Oriosvaldo de Moura.
} 
busca adentrar no entendimento dos princípios da AOE e no conceito de situações desencadeadoras de aprendizagem - SDA, desenvolvidas intencionalmente por meio de jogos, histórias virtuais e situações emergentes do cotidiano em pesquisas acadêmicas vinculadas ao grupo.

Assim, o presente texto busca responder a seguinte problemática: Como as situações desencadeadoras de aprendizagem têm sido viabilizadas em pesquisas acadêmicas a partir do recurso a os jogos, às histórias virtuais e às situações emergentes do cotidiano, em consonância com os princípios da AOE?, o que nos levou ao objetivo de investigar como as SDA podem ser elaboradas e/ou organizadas na intenção da apropriação de um conceito matemático. Com esse estudo, espera-se contribuir para a apropriação do conceito de AOE nas pesquisas e superar possíveis fragilidades na elaboração de situações de ensino que se pautem nesse conceito, evitando-se, por exemplo, entendimentos equivocados do recurso à história virtual como um mero uso da contação de trechos da história da matemática ou mesmo o recurso ao jogo como um complemento do tempo educativo ou destinado à memorização de conceitos.

O caminho metodológico adotado se deu a partir do levantamento de 50 (cinquenta) pesquisas de mestrado e doutorado que envolvem o conceito de AOE, em trabalhos vinculados diretamente aos pesquisadores do GEPAPe ou de seus orientandos diretos. O ponto de partida para acesso aos trabalhos foi o vínculo dos trabalhos no Currículo Lattes dos orientadores vinculados ao grupo, partindo-se dos trabalhos orientados pelo Prof. Dr. Manoel Oriosvaldo de Moura, líder do grupo. A partir dos títulos dos trabalhos de mestrado e/ou doutorado dos integrantes do GEPAPe e de seus orientandos diretos, a definição do corpus de análise se deu pela busca nos títulos, resumos e palavras-chave a partir das expressões Atividade Orientadora de Ensino e/ou Atividade Orientadora. A análise foi realizada por meio do estudo das SDA presentes nas pesquisas. 


\section{Do conceito de atividade à Atividade Orientadora de Ensino}

Os fundamentos teórico-metodológicos da Atividade Orientadora de Ensino, cujos pressupostos estão ancorados na Teoria Histórico-Cultural e na Teoria da Atividade, revelam um modo de organização do ensino para que a escola se ocupe da educação escolar, a qual se entende como espaço adequado para a apropriação dos conhecimentos teóricos pelos estudantes, patrimônio cultural da humanidade e que, por conseguinte, conduzem à humanização.

O conceito de AOE pauta-se nos elementos do conceito de atividade de Leontiev (motivos, necessidades, ações e operações, entre outros) e é estruturado a partir de princípios sustentados pela THC, dentre eles: a coletividade, o movimento lógico histórico, a intencionalidade pedagógica e o papel da mediação no processo educativo. Araújo (2019) explicita os elementos da atividade em duas dimensões mencionando que:

[...] atividade se caracteriza por duas dimensões que se interdependem, uma de execução e outra de orientação. $\mathrm{Na}$ dimensão da orientação poderíamos considerar o motivo e o objeto para o qual ele se orienta. De tal forma que o motivo e o objeto se vinculam a uma determinada necessidade. As ações e operações configuram a dimensão executora da atividade, na qual os objetivos se relacionam com as ações e as condições com as operações. (p.130).

Moura, Araújo e Serrão (2018, p. 414) apontam que "[...] nenhum indivíduo da espécie é capaz de produzir sua existência sozinho", dessa forma é necessário que a criança tenha contato com outros seres humanos e, ao se comunicar com estes, aprenda sua atividade de forma adequada. A este processo, Leontiev denomina educação. Os autores ainda trazem a visão de Vygotski de que o conceito, que é objeto da educação escolar, é provido da história humana que o produziu, já que "[...] o conceito está encarnado na palavra e esta tem um significado construído historicamente, então devemos atentar para o conceito" (MOURA, ARAÚJO e SERRÃO, 2018, p. 415).

Considerando a estrutura de atividade proposta por Leontiev, Moura (1996) propõe o conceito de Atividade Orientadora de Ensino como um modo 
geral de organização da atividade pedagógica, compreendida como uma unidade entre a atividade de ensino realizada pelo professor e a atividade de aprendizagem do estudante, uma vez que essa se constitui a partir de:

[...] uma necessidade (apropriação da cultura), um motivo real (apropriação do conhecimento historicamente acumulado), objetivos (ensinar e aprender) e propõe ações que considerem as condições objetivas da instituição escolar. (MOURA et al, 2016, p. 110).

Segundo os autores Moura, Araújo e Serrão (2018),

Os fundamentos teórico-metodológicos da $\mathrm{AOE}$, cujos pressupostos estão ancorados na teoria histórico-cultural e na teoria da atividade, são indicadores de um modo de organização do ensino para que a escola cumpra sua função principal, que é possibilitar a apropriação dos conhecimentos teóricos pelos estudantes e o desenvolvimento de suas personalidades. Assim, a AOE, como mediação, é instrumento do professor para realizar e compreender seu objeto: o ensino de conceitos. E é instrumento do estudante que age rumo à apropriação de conhecimentos teóricos a serem objetivados pela AOE. Desse modo, a AOE tem as características de fundamento para o ensino e é também fonte de pesquisa sobre o ensino. (p. 421).

No conjunto de características que fundamentam o conceito de AOE, Moraes (2008) destaca os seguintes:

- a intencionalidade pedagógica;

- a situação desencadeadora de aprendizagem é a materialização da atividade de ensino;

- a essência do conceito;

- a mediação é condição fundamental para o desenvolvimento da atividade;

- a necessidade do trabalho coletivo;

- torna-se uma atividade do sujeito (p. 232).

No processo de elaboração das SDA é fundamental que as referidas características da AOE sejam consideradas e tomadas como ponto de partida para o movimento de estudo e produção escrita das situações.

As situações desencadeadoras de aprendizagem são aquelas que possibilitam criar condições reais para que os sujeitos se coloquem em atividade 
de aprendizagem, apropriando-se assim de conceitos que foram construídos historicamente (MOURA, SFORNI e LOPES, 2017). Por meio delas, é possível vivenciar o movimento intencional da atividade pedagógica, propiciando aos sujeitos a formação de seu pensamento teórico (CEDRO, 2008).

Segundo Moura, Araújo e Serrão (2018, p. 422)

Tal como no desenvolvimento histórico e social, a situação desencadeadora de aprendizagem visa colocar a criança em tensão criativa, à semelhança daqueles que a vivenciaram, ao resolver seus problemas autênticos, gerados pelas necessidades de ordem prática ou subjetiva. Essas situações desencadeadoras de aprendizagem podem propor um problema capaz de mobilizar o indivíduo ou o coletivo para solucioná-lo.

$\mathrm{Na}$ organização das situações desencadeadoras de aprendizagem é essencial ter como referência o desenvolvimento histórico e lógico do conceito em foco, compreendido como produção humana. Na mesma medida, cabe eliciar ações coletivas para a resolução do problema desencadeador, uma vez que

[...] a apropriação do conhecimento teórico só é possível por meio da intencionalidade do professor que compreende o coletivo como espaço de produção e apropriação da cultura humana historicamente produzida (CEDRO, MORETTI e MORAES, 2018, p. 441).

O conceito de problema desencadeador, entendido como um problema de aprendizagem, “[...] está estreitamente ligado ao de ação cognitiva, a qual se caracteriza principalmente pelo modo de analisar um objeto" (RUBTSOV, 1996, p. 133) e à aquisição de conhecimentos teóricos. Nesse sentido, entendese a escola, ambiente promotor da educação escolar, como lócus privilegiado para apropriação de conhecimentos teóricos, de modo que:

Esta compreensão da escola como espaço de apropriação do conhecimento mais elaborado pela humanidade e, portanto, de aprendizagem de um tipo particular de conhecimento, que é o conhecimento teórico, é discutida por Rubtsov (1996, p. 129) ao afirmar que o pensamento teórico relaciona-se com o conhecimento teórico que "repousa numa análise do papel e da função de uma certa relação entre as coisas no interior de um sistema", 
contrapondo-se ao conhecimento empírico fundamentado na compreensão entre os objetos e suas representações. (PANOSSIAN, MORETTI e SOUZA, 2017, p. 129).

A proposição das chamadas SDA ocorre por diferentes recursos metodológicos, entre eles, o jogo, a situação emergente do cotidiano e a história virtual, mencionadas em MOURA et al. (2016). Porém deve-se compreender que não é "o" jogo, "a" situação emergente ou "a" história virtual por si só que constituem as situações desencadeadoras de aprendizagem. Para que estes recursos sejam considerados potenciais para concretizar situações desencadeadoras de aprendizagem precisam colocar o estudante ante uma situação-problema análoga à vivenciada pelo homem ao lidar com conceitos matemáticos. Além disso, a solução dessa situação-problema deve ser realizada coletivamente pelos estudantes e possibilitar a síntese da solução coletiva. É a mediação do professor, a forma como irá orientar a SDA que acarretará ou não alcançar o seu objetivo. Segundo Moura, Araújo e Serrão (2018, p. 423),

Essas situações desencadeadoras de aprendizagem têm em comum a possibilidade de conter potencialmente o problema gerador da tensão que coloca os sujeitos em atividade. No caso da educação escolar, a situação desencadeadora de aprendizagem visa, necessariamente, à apropriação de conhecimentos considerados relevantes do ponto de vista social, para que o sujeito esteja munido com ferramentas teóricas, metodológicas e éticas que lhe proporcionem a participação de modo pleno na comunidade à qual pertence.

Assim, as SDA são organizadas por momentos essenciais para sua constituição descritas por Araújo (2019). São eles: apresentação do problema (que envolve uma necessidade social), discussão e compreensão do problema (por meio das hipóteses, compreensão da linguagem e estruturação do pensamento, por meio do compartilhamento), testagem das hipóteses (primeiras compreensões do conceito estudado, tendo em vista seus nexos conceituais), definição de uma solução (escolha da hipótese mais adequada ao problema) e utilização da solução (que gera a produção da "resposta" e criação de um modelo conceitual). 
Além dos momentos apresentados por Araújo, destacamos os princípios de análise e síntese da avaliação permanente de toda a situação desencadeadora de aprendizagem como um momento de seu desenvolvimento.

Para que se estabeleçam os possíveis encaminhamentos, o professor necessita estar em atividade de ensino, a fim de mobilizar os seus estudantes, de modo que também os possibilite estar em atividade. Essa organização, desde a apresentação do problema, deverá ser adequada ao nível e interesse dos estudantes, proporcionando que estes se coloquem como parte do contexto apresentado pela SDA. Através dessa consciência do problema o estudante pode encontrar o motivo para buscar a sua solução, por meio das discussões, testagens e definição da solução, pois é somente pelo compartilhar desses princípios que a tensão criativa é impulsionadora da atividade de aprendizagem.

Esse movimento da atividade pedagógica, possibilitado pelas situações desencadeadoras de aprendizagem, acontece de modo intencional para a apropriação de conceitos. Nesse sentido, "apropriar se de um conceito é, portanto, apropriar-se de uma atividade historicamente elaborada e que deu origem àquele conceito" (NASCIMENTO e MOURA, 2018, p. 56).

Compreender o conceito de AOE envolve o entendimento de um modo geral de organização do ensino, motivo pelo qual define-se a AOE como base teórico-metodológica para o ensino, ou seja, não se trata simplesmente de estruturar determinada metodologia de ensino - base metodológica, mas um modo de organizar o ensino que considera a educação escolar como lócus de formação humana e apropriação do conhecimento historicamente construído - base teórica, tudo isso embasado na Teoria Histórico-Cultural (THC) e na Teoria da Atividade (TA).

A figura a seguir representa esquematicamente o lugar das situações desencadeadoras de aprendizagem na Atividade Orientadora de Ensino: 
FIGURA 1: A situação desencadeadora de aprendizagem na AOE.

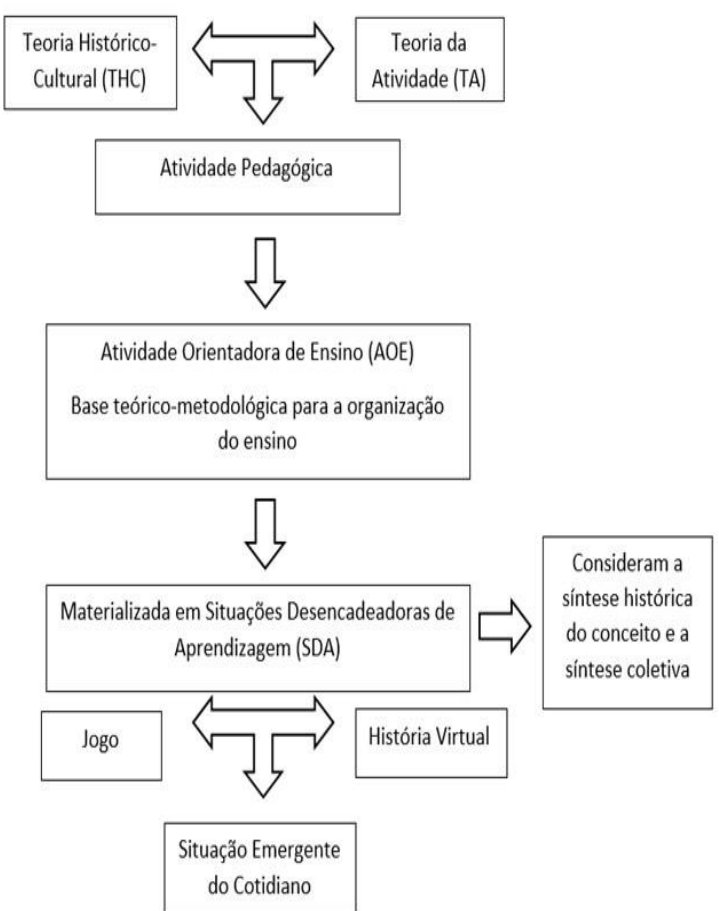

Fonte: Elaborado a partir da estrutura da AOE (MOURA, 2016).

\section{Metodologia}

Os dados de pesquisa foram coletados a partir dos trabalhos produzidos no GEPAPe, sob orientação do Prof. Dr. Manoel Oriosvaldo de Moura e de seus orientandos que também se debruçaram a orientar pesquisas envolvendo a AOE. O acesso se deu pela busca das pesquisas nos currículos Lattes dos pesquisadores, partindo das pesquisas orientadas por Moura, seguido da consulta aos trabalhos orientados pelos seus ex-orientandos, vinculados ao grupo de pesquisa. Localizadas as pesquisas registradas nos currículos Lattes, a seleção se deu a partir daquelas que envolvessem o termo AOE no resumo e/ou nas palavras-chave, com acesso ao texto integral desses 
trabalhos. Foram analisadas um total de 50 (cinquenta) pesquisas ${ }^{6}$, sendo 40 (quarenta) de mestrado 7 e 10 (dez) de doutorado ${ }^{8}$.

A pesquisa pautou-se, inicialmente, em duas etapas: a) levantamento de pesquisas orientadas por MOURA, entre 2002 e 2019, que tenham a AOE no título, resumo ou palavras chave; b) levantamento de pesquisas orientadas pelos orientandos de MOURA, entre 2002 e 2019, que tenham a AOE no resumo ou palavras chave. Em seguida, sucedeu-se a análise das pesquisas envolvendo o levantamento de:

- pesquisas que envolvem a formação (inicial ou continuada) e o ensino (Educação Infantil, anos iniciais, anos finais do Ensino Fundamental e Ensino Médio);

- situações desencadeadoras de aprendizagem presentes nas pesquisas sob a forma de jogos, situações emergentes do cotidiano e histórias virtuais;

- conhecimentos matemáticos presentes nas situações desencadeadoras de aprendizagem nos eixos Números e Operações, Pensamento Algébrico, Geometria, Grandezas e Medidas, Educação Estatística.

A organização dessas categorias de análise possibilitou a apresentação de um panorama geral de pesquisas que envolvem o conceito de AOE e a elaboração de situações desencadeadoras de aprendizagem para o ensino de matemática, apresentado a seguir.

\section{O panorama das pesquisas que envolvem a $\mathrm{AOE}$}

Do conjunto de pesquisas analisadas, 34 delas são voltadas à formação de professores e 16 ao ensino, e foram publicadas no período de

\footnotetext{
${ }^{6} \mathrm{O}$ levantamento de pesquisas totalizou 53 (cinquenta e três) trabalhos, mas somente 50 (cinquenta) deles foram localizados na íntegra e, por conseguinte, compuseram a análise.

${ }^{7}$ Autores das dissertações: Aguiar (2018), Amaral (2018), Amorin (2015), Barros (2007), Bellini (2017), Bemme (2015), Binsfeld (2019), Branco (2018), Brito (2017), Carvalho (2017), Cedro (2004), Durgante (2019), Euzébio (2015), Ferreira (2017), Fraga (2013), Fraga (2016), Gabbi (2018), Giacomelli (2019), Hundertmarck (2017), Lemes (2012), Locatelli (2015), Lucion (2015), Marafiga (2017), Milani (2016), Moraes (2017), Moraes (2018), Perlin (2014), Pozebon (2014), Ritzmann (2009), Romeiro (2017), Santos (2016), Silva (2008), Silva (2012), Silva (2014), Silva (2018), Silva (2019), Teza (2018), Trindade (2017), Vaz (2013), Zeferino (2016).

${ }^{8}$ Autores das teses: Araújo (2015), Borowsky (2017), Costa (2016), Fraga (2017), Gladcheff (2015), Migueis (2010), Moraes (2008), Moretti (2007), Sarmento (2019), Virgens (2019).
} 
2002 a 2019. Não foram localizados trabalhos anteriores a 2002 que envolvam a AOE. Os dados a seguir indicam a frequência desses trabalhos em cada uma das duas categorias - formação e ensino.

TABELA 1: Pesquisas que envolvem AOE na formação e no ensino.

\begin{tabular}{c|c|c}
\multirow{2}{*}{ FORMAÇÃO } & Inicial & 13 \\
\cline { 2 - 3 } & Continuada & 21 \\
\hline \multirow{3}{*}{ ENSINO } & Educação infantil & 1 \\
\cline { 2 - 3 } & Anos iniciais & 8 \\
\cline { 2 - 3 } & Anos finais & 5 \\
\cline { 2 - 3 } & Médio & 2 \\
\hline TOTAL & & 50
\end{tabular}

Fonte: as autoras (2020).

Na busca pela materialização da AOE nas situações desencadeadoras presentes nas pesquisas, foi possível elencar nas pesquisas o recurso aos jogos, às histórias virtuais e às situações emergentes, sendo que em algumas delas mais de um dos recursos é adotado, conforme segue:

TABELA 2: Tipos de SDA nas pesquisas.

\begin{tabular}{l|l} 
Jogo e História Virtual & 16 \\
\hline História Virtual & 15 \\
\hline Jogo & 07 \\
\hline Situação Emergente do cotidiano & 01 \\
\hline Jogo e Situação Emergente & 01 \\
\hline História Virtual e Situação Emergente & 01
\end{tabular}

Fonte: as autoras (2020).

Nas pesquisas foi possível reconhecer a menção a 62 histórias virtuais, 55 jogos e 3 situações emergentes do cotidiano. Das histórias virtuais as que mais se repetiram nos trabalhos foram: "Carta Caitité", 
"Cleópatra" e "O curupira", e os principais temas comuns entre elas: "Egito", "Sítio do picapau amarelo" e "Povo Papuas". Nos jogos, "Boliche", "Jogo de varetas ou Pega varetas" e "Batalha Naval" foram os mais citados. Nas situações emergentes, todas possuem títulos e temas diferentes entre si, o que se justifica pela própria natureza da situação que advém de diferentes contextos das realidades a que se referem.

Em relação aos conceitos matemáticos presentes nas SDA, evidenciase maior concentração de situações relacionadas ao eixo de conhecimento matemático "Números e Operações". Tomando-se por referência a organização dos conhecimentos matemáticos identificamos os seguintes:

TABELA 3: Eixos de conhecimentos matemáticos nas SDA.

\begin{tabular}{l|l} 
Números e Operações & 22 \\
\hline Grandezas e Medidas & 13 \\
\hline Educação Estatística & 07 \\
\hline Geometria & 06 \\
\hline Pensamento Algébrico & 05
\end{tabular}

Fonte: as autoras (2020).

Com o intuito de discutir como as SDA tem se materializado nas pesquisas acadêmicas por meio dos jogos, histórias virtuais e situações emergentes do cotidiano, à luz dos princípios da AOE, a etapa final desse estudo busca ilustrar o modo como essas SDA vem sendo exploradas, de modo a promover a apropriação conceitual de conhecimentos matemáticos, tendo como referência a aprendizagem do conceito e a coletividade como elementos fundantes da base teórico-metodológica da AOE.

Assim, do conjunto de situações desencadeadoras presentes nas pesquisas analisadas, optou-se por trazer alguns indícios do modo de organização de ensino presente nas situações em si e nos 
encaminhamentos propostos tanto em trabalhos voltados para a formação docente quanto em trabalhos voltados ao ensino.

\section{O movimento das situações desencadeadoras}

Com o intuito de revelar indícios do movimento de organização do ensino de matemática presente nas situações desencadeadoras constantes das pesquisas, foram escolhidas algumas situações para ilustrar a discussão, que se apresenta na sequência. A escolha se deu a partir de dois critérios centrais: SDAs mais presentes nas pesquisas ou SDAs descritas mais detalhadamente nos trabalhos.

\section{Ilustrando situações envolvendo a História Virtual como SDA}

Com a finalidade de ilustrar o movimento da história virtual como situação desencadeadora de aprendizagem, a seguir serão apresentadas três histórias virtuais presentes nas pesquisas acadêmicas em análise: Pastor Linus, Verdim e seus amigos e Carta Caitité, evidenciando o modo de apresentação das mesmas, embasadas nos pressupostos da AOE.

$\mathrm{Na}$ história virtual do conceito intitulada Pastor Linus, a autora apresenta o problema desencadeador da seguinte forma:

Há muito tempo atrás, o pastor Linus, contava suas ovelhas guardava uma pedra para cada animal. Certo dia, mostrou para seu vizinho Petrus a quantidade de ovelhas de seu rebanho. Petrus alertou o amigo dizendo-lhe que se o rebanho aumentar consideravelmente irá carregar muita pedra e acabou criando um problema para Linus: "Como contar a mesma quantidade com menos pedra? (MORAES, 2008, p. 256)

Observa-se por meio do problema desencadeador que o estudante é motivado a atender uma necessidade. Para a resolução da proposta, o estudante é convidado a trabalhar de forma individual e sequencialmente coletiva e cooperativa, conforme descrito pela autora Moraes (2008): 
1. Distribuir para os grupos, dezessete pedrinhas ou unidade do material dourado que representam a quantidade de ovelhas de Linus;

2. Solicitar que os alunos resolvam o problema, individualmente, por meio de um desenho;

3. Discutir em grupos de três ou quatro pessoas as soluções criadas;

4. Escolher uma solução para cada grupo, que abranja todos os casos de contagem;

5. Solicitar para que os grupos apresentem a solução para a classe no retroprojetor;

6. Escolher uma das criações para ser utilizada pela classe para efetuar contagens diversas; Exemplo: contar a quantidade 23 a partir da criação da classe, o número de alunos.

7. Registrar o ano de 2006 com a contagem escolhida (p. 256).

$\mathrm{Na}$ pesquisa mencionada, apresentam-se os movimentos do desenvolvimento da atividade na busca por atender o objetivo de desenvolver o conceito de base.

Um aspecto importante que anuncia os pressupostos da AOE é a apresentação da proposta junto a um problema desencadeador, característica esta, específica das histórias virtuais e das demais formas de estruturação das SDA que envolvem o jogo e as situações emergentes.

A seguir destacamos o exemplo da história virtual "Verdim e seus amigos". Esta situação desencadeadora de aprendizagem está inserida na pesquisa de Araújo (2015) e foi realizada no processo de formação docente proposta pelo Projeto Observatório da Educação (OBEDUC), intitulado Educação Matemática nos Anos Iniciais do Ensino Fundamental: princípios e práticas da organização do ensino ${ }^{9}$. A história é apresentada na figura a seguir:

\footnotetext{
${ }^{9}$ Projeto em rede desenvolvido de 2011 a 2015 e composto por professores da Educação Superior, estudantes da graduação, professores, supervisores e/ou coordenadores da Educação Básica, formado pelas seguintes IES: USP (São Paulo); USP (Ribeirão Preto), UFG e UFSM, com apoio da CAPES. Consulta em http://www.labeduc.fe.usp.br/?post_type=labs\&p=1295.
} 
FIGURA 2: Verdim e seus amigos.

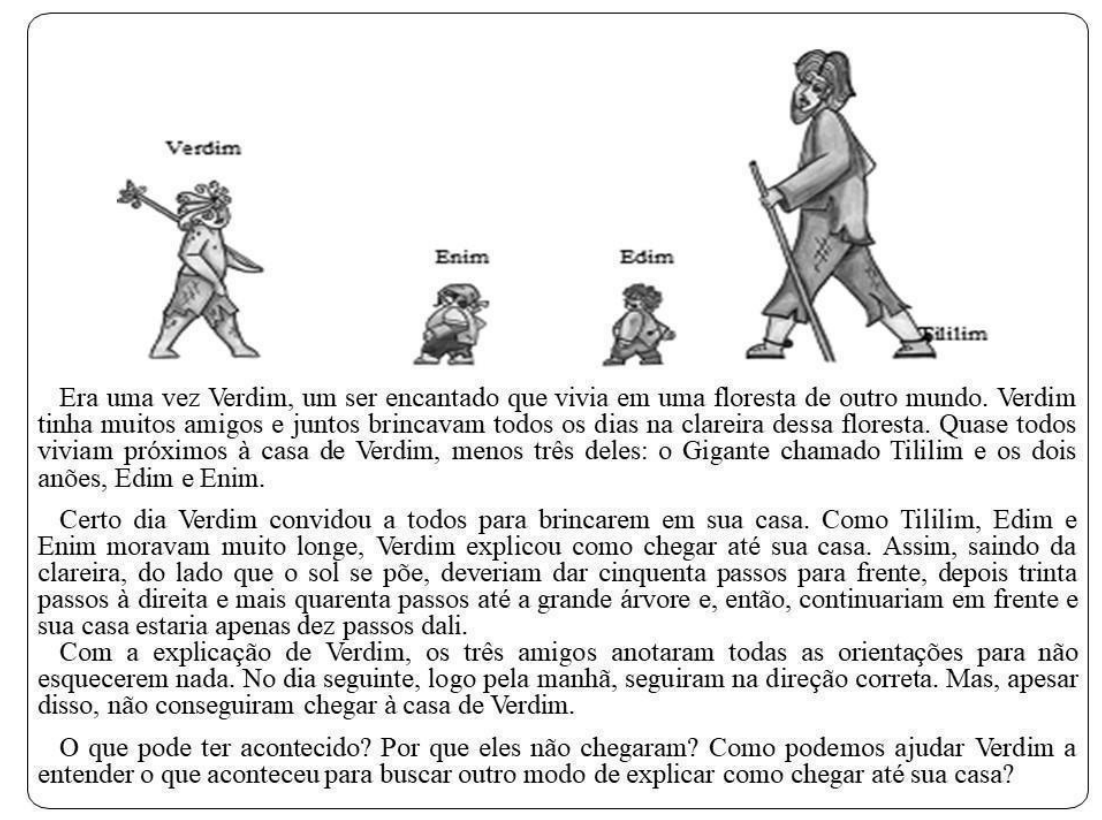

Fonte: ARAUJO (2015, p. 123).

A história virtual Verdim e seus amigos foi intencionalmente apresentada aos participantes desta formação objetivando que os mesmos percebessem a necessidade da humanidade em criar uma unidade de medida padrão. O conceito de medida foi trabalhado a partir dos seguintes problemas desencadeadores:

- O que pode ter acontecido?

- Por que os amigos de Verdim não conseguiram chegar à sua casa?

- Como podemos ajudar Verdim a descobrir o que aconteceu e, assim, buscar outro modo para explicar a seus amigos como chegar até à sua casa? (ARAUJO, 2015, p. 122).

A vivência com esta situação de ensino, num processo de formação docente, permitiu discutir, coletivamente, alguns conceitos descritos pelo pesquisador, tais como: atividade, ação, significado, sentido, papel da mediação e a gênese dos conceitos matemáticos e como esses conceitos se relacionam com o ensino. $\mathrm{Na}$ perspectiva vivenciada com os professores, espera-se criar condições para que os professores reconheçam esse modo geral de organização do ensino ao pensarem suas práticas pedagógicas. 
A Carta Caitité é uma SDA em forma de história virtual, cujo problema desencadeador "[...] refere-se a descobrir o preço de um jegue que estava escrito em um sistema de numeração desconhecido" (BEMME, 2015, p. 156). Deste modo, visa trabalhar os conceitos fundamentais de um sistema de numeração, colocando o sujeito frente a necessidade desses conceitos. A história é mencionada em várias das pesquisas e tem sua elaboração de autoria de Moura, que desenvolveu o conceito da AOE. Bemme (2015) menciona em sua pesquisa que seus colaboradores, professores em formação inicial, falharam em uma primeira tentativa de resolução, ao tentar transpor os dados da carta para a base dez. Isso os levou a se questionarem se a escrita numérica na carta estava na base 10 e, por conseguinte:

[...] desencadeou uma discussão sobre o que constituiu a base de um sistema e sua relação com a quantidade de símbolos. Essas reflexões levaram à solução do problema que, na verdade, não se centrava simplesmente em descobrir o valor do jegue, mas sim na organização do sistema de numeração no qual estava escrito esse valor (BEMME, 2015, p. 156).

Destarte, precisaram refletir sobre a organização do Sistema de Numeração Decimal de uma forma diferente da que normalmente é considerada ao ensinar.

Moraes (2008) apresenta parte da intervenção das pesquisadoras através de questionamentos baseados nos elementos estruturantes da atividade, que auxiliou os alunos na solução deste mesmo problema. A autora enfatiza que os questionamentos devem ser formulados de modo a mobilizar o pensamento dos participantes, colocando-os em movimento, mas sem resolver o problema para eles. A seguir, um trecho dessa mediação:

Co - Qual é a necessidade de resolução dessa situaçãoproblema? (Silêncio). Vejam no contexto da carta, é preciso que os universitários de São Paulo descubram a lógica do sistema de numeração dos Caitités. Então, instala-se aqui uma necessidade para os universitários e, nesse momento, para nós. Como podemos descobrir essa lógica?

Co - Quantos símbolos os Caitités possuem para representar os diferentes numerais? Há uma lógica para a representação? 
Se há uma lógica como ela se expressa para a representação de qualquer numeral?

Ma - Então, vamos ver por onde começamos? (MORAES, 2008, p. 144).

$\mathrm{Na}$ pesquisa de Branco (2018), aponta-se também a importância do coletivo nesse processo, enfatizando que os próprios participantes de sua pesquisa solicitaram que a atividade fosse feita em grupo, e apresenta a opinião de uma professora participante:

É que em grupo a gente pensa melhor. Podemos trocar experiências e ouvir a opinião do outro. Sozinho você reduz a possibilidade de resolução desse dilema. Além do mais, a gente se sente mais seguro quando se está entre os colegas (Rute, E4, A, apud BRANCO, 2018, p. 78).

Outra professora também enfatiza que a situação é muito difícil de ser realizada individualmente por eles professores, e mais ainda por seus alunos do sexto ano.

Virgens (2019) alude que a Carta Caitité pode suscitar "[...] uma necessidade relacionada à lógica de organização do sistema numérico que poderia ser desencadeadora da aprendizagem do nosso próprio sistema de numeração" (VIRGENS, 2019, p. 134). Essa forma diferencia-se de outras abordagens onde são apresentados alguns sistemas de numeração antigos com suas regras de composição e busca-se identificar os números escritos nesses sistemas, a "[...] "conversão" de números do "nosso" sistema para esses outros, ou vice-versa, ou da utilização desses números de outros sistemas em contextos atuais, como no caso do sistema romano de numeração" (VIRGENS, 2019, p. 134).

\section{Ilustrando situações envolvendo jogos como SDA}

Para ilustrar o movimento do jogo como situação desencadeadora de aprendizagem selecionou-se recortes de três jogos mencionados nas pesquisas: o Ponto a Ponto, o Boliche e o Pega-varetas. A discussão que segue busca revelar manifestações do modo como o trabalho com cada um desses jogos, à luz dos pressupostos da AOE, possibilita a apropriação de conceitos. 
No jogo "Ponto a Ponto" as regras apresentadas em Aguiar (2018) indicam:

1. Em cada rodada o jogador deve escolher um número natural do 6 ao 19 ;

2. O jogador deve comunicar o número escolhido aos demais participantes e, em seguida, lançar o dado;

3. O número escolhido deve ser dividido mentalmente pelo número obtido no lançamento do dado;

4. Se a divisão der exata, o jogador não marca ponto e se não der exata, ou seja, sobrar resto, ganha um ponto;

5. O vencedor é aquele que acumular mais pontos ao término de dez jogadas; (p. 113).

Na pesquisa mencionada, o jogo é abordado em um processo de formação de professoras em serviço. A vivência do jogo tem a intenção de mobilizar as professoras para um modo geral de organização da atividade de ensino que desencadeia a aprendizagem conceitual. Assim, ao iniciarem as jogadas, tanto os escolares, como as professoras escolhem os números aleatoriamente e à medida em que sucedem as jogadas e que interagem entre elas, vão reconhecendo algumas qualidades dos números e modificando suas escolhas do 6 ao 19. Ao final do jogo, a pesquisadora propõe algumas questões desencadeadoras e finaliza com o problema desencadeador central, conforme se pode observar:

1. Ao escolher números de 6 a 19, quais deles apresentam menor chance de marcar ponto ao lançar o dado? Comente como você obteve sua resposta.

2. Quais números do 6 ao 19 apresentam maior chance de marcar ponto ao lançar o dado? Que características podem ser identificadas nesses números?

3. Para ser bem sucedido no jogo, existem números mais indicados para escolher no momento de jogar? Quais? Por quê? Registre como chegou às conclusões. (AGUIAR, 2018, p. 113).

A discussão coletiva das questões desencadeadoras associada ao registro das percepções com os números mais bem sucedidos em uma tabela permite que as professoras identifiquem que os números divisíveis somente por 1 ou por ele mesmo, do 6 ao 19, são os melhores, ou seja, os números primos. Dessa compreensão, novas aprendizagens podem ser desencadeadas, tais como o estudo de chances de sucesso ao jogar o dado. 
No jogo de Boliche a autora Carvalho (2017) tem por objetivo “[...] reconstruir a ideia do sistema de numeração decimal posicional (SND)" (p. 150). Para o desenvolvimento do jogo os pinos foram numerados de um a dez, sendo que cada pino teria um valor de pontuação somado à quantidade de pinos derrubados, distribuídos em uma tabela apresentada aos estudantes. Durante a atividade os alunos acompanharam por meio de uma folha de registro seus pontos (CARVALHO, 2017).

Foram realizadas três rodadas do jogo, e a mobilização do grupo de alunos teve início com:

[...] os estudantes foram informados que deveriam realizar a contabilização dos pontos de todos os participantes e converter a pontuação em tampinhas, transferindo os pontos acumulados nas caixas (das unidades, das dezenas e das centenas) na relação 'um ponto - uma tampinha'. Logo os alunos perceberam que isso não seria possível, pois não havia tampinhas suficientes para todos os pontos (CARVALHO, 2017, p. 152)

Aponta-se aqui, a essência do uso do jogo como situação desencadeadora de aprendizagem. A partir da orientação dada aos alunos, desenvolve-se a discussão em roda de conversa para resolver o conflito que se apresenta. As professoras que medeiam a situação instigam os estudantes a pensar como podem utilizar as tampinhas para representar os pontos. Nesse movimento,

[...] as professoras ressaltaram o movimento dos homens para organizar e contabilizar grandes quantidades, assim como os problemas pelos quais passaram até chegar no modo de organização numérica a que temos acesso hoje, o SND. (CARVALHO, 2017, p. 152).

Na pesquisa de Cedro (2004) o Jogo de Varetas "[...] foi utilizado com o objetivo do desenvolvimento dos nexos conceituais de dois dos movimentos de controle das quantidades: a ideia da organização em agrupamentos e da divisão" (p. 106) com estudantes da quinta série do Ensino Fundamental de uma escola de aplicação da USP, vinculada ao Clube de Matemática, sob a forma de um experimento didático. 
Neste experimento, a SDA, materializada neste jogo, foi organizada como uma das atividades de ensino elaboradas e analisadas no Clube de Matemática como espaço de aprendizagem. O jogo de varetas seguiu suas regras originais, somente a pontuação foi alterada. $\mathrm{O}$ foco estava nos registros realizados pelos estudantes em cada jogada.

Na vivência com o jogo, o pesquisador ressalta que é:

[..] um momento de interação com os alunos, em que o objetivo da mediação do professor é demonstrar a importância da realização dos registros, do estabelecimento das relações envolvidas na atividade desenvolvida com o jogo de varetas. $\mathrm{Na}$ interação do professor evidenciamos a tentativa de fornecer uma autonomia às crianças por meio do desenvolvimento de um contexto crítico. Esse fato se dá quando o professor deixa claro às crianças que cada uma deve fazer o seu registro independentemente. (CEDRO, 2004, p. 106).

Destacamos aqui uma das características que fundamentam o conceito da AOE: a mediação entre a atividade de ensino e a atividade de aprendizagem. Cedro (2004) enfatiza que "Após esse momento de interação entre professor e os alunos, percebemos nos registros a influência positiva da mediação do professor" (p. 107). Por meio desses registros, o autor constatou a ideia multiplicativa ao registrar os pontos obtidos na partida, atingindo o objetivo com o trabalho com o jogo.

\section{Ilustrando situações emergentes do cotidiano como SDA}

Seguidas das ilustrações envolvendo as histórias virtuais e os jogos, apresentam-se, a seguir, duas situações emergentes do cotidiano, a fim de ilustrar seu movimento como SDA. Nesse cenário são apresentadas e discutidas as SDAs intituladas: problemas de Medidas e Viagem a Mata.

Costa (2016) apresenta um problema de medida em forma de situações emergentes do cotidiano da escola, apresentado por uma professora participante da pesquisa, e que está descrita a seguir: 
A professora de educação física precisa saber o tamanho deles em ordem crescente, a altura deles bem certinho, para fazer algumas atividades que precisam que eles estejam em ordem crescente, os meninos e as meninas. Como fazer para que a gente possa definir certinho quem é o da frente quem vai ser o último e quem vai ser o do meio? (COSTA, 2016, p. 122).

O autor aponta que, por configurar-se como uma situação real para as crianças, objetivo das situações emergentes do cotidiano, elas entraram em atividade ao buscar uma solução para este problema. Essa SDA “[...] despertou nos alunos a necessidade de se apropriar do conceito de medida de comprimento ainda que primeiramente de uma forma elementar, por meio da medição da sua própria altura" (COSTA, 2016, p. 122). Com o surgimento das primeiras dúvidas e soluções, e da operacionalização desta e das próximas ações, o autor alude que foi ocorrendo, de forma gradativa, a aproximação da apropriação do conceito.

A segunda situação emergente do cotidiano ilustrada no presente texto encontra-se na dissertação de Silva (2014). A temática para a situação decorreu de uma proposta de viagem anual com alunos de uma turma do quinto ano do Ensino Fundamental. Mata é uma cidade, próxima de Santa Maria, no Rio Grande do Sul, considerada um ponto turístico na região. O ponto de partida para desencadear as ações de ensino consistiu em investigar quantas das crianças na escola já conheciam a cidade da Mata. Em seguida, procederam estudos sobre a região e buscaram dar respostas ao seguinte problema desencadeador: "De que maneira podemos organizar os dados que coletamos para compreendermos e divulgarmos de forma mais rápida as informações contidas em nossa pesquisa?" (SILVA, 2014, p. 65).

Diante do enfrentamento do problema desencadeador, os conhecimentos estatísticos foram mobilizados à medida em que precisavam selecionar as melhores estratégias para organizar e apresentar os dados, advindos da realidade da temática emergente. 


\section{Conclusão}

Considerando a intenção inicialmente apresentada, de contribuir para a apropriação do conceito de Atividade Orientadora de Ensino nas pesquisas e para a superação de possíveis fragilidades na elaboração de situações de ensino que se pautem nesse conceito, tomamos como referência o levantamento de pesquisas que envolvem o ensino e a formação de professores que ensinam matemática à luz dos princípios da $\mathrm{AOE}$.

Nessa perspectiva, procurou-se destacar o modo geral como essas SDAs são apresentadas tanto nos processos de ensino na Educação Básica quanto nos processos de formação de professores, destacando-se o movimento de síntese histórica do conceito e de síntese coletiva.

A compreensão do problema desencadeador na elaboração de situações desencadeadoras de aprendizagem para a aprendizagem de um conceito e o modo de ação na situação de ensino envolvendo a coletividade figuram como aspectos centrais no movimento das SDAs envolvendo jogos, histórias virtuais e situações emergentes do cotidiano, presentes nas pesquisas.

Nas pesquisas analisadas percebeu-se que a vivência com situações desencadeadoras de aprendizagem nos processos formativos, contribuiu com o processo de significação das ações de aprendizagem para a atividade de ensino de matemática dos sujeitos. As ações coletivas, desenvolvidas no decorrer do processo, bem como o papel da mediação, o estudo da essência dos conceitos matemáticos e como esses conceitos se relacionam com o ensino cria condições para a apropriação do pensamento teórico desses sujeitos por meio da articulação entre a AOE e os conceitos matemáticos, fazendo com que esse modo de organização da atividade de ensino de matemática seja desencadeado.

As ilustrações de SDAs em algumas pesquisas procuraram evidenciar o modo geral de formação e organização do ensino em consonância com os pressupostos da AOE. Esses recortes intentam explicitar um movimento que busca superar a simples proposição de jogos ou a mera contação de trechos da 
história da matemática, como um caminho para o ensino e que muitas vezes, não desencadeiam a aprendizagem, ou seja, não possibilitam a unidade dialética entre ensino e aprendizagem.

Nesse sentido, os recortes não esgotam as possibilidades de organização do ensino, mas ao contrário, buscam destacar alguns aspectos aqui pontuados num movimento de síntese provisória do presente estudo: a necessidade do reconhecimento do problema desencadeador na SDA; as características do problema desencadeador que possibilitem aproximar os sujeitos do movimento histórico do conceito matemático; a dinâmica da SDA que favoreça o compartilhamento e a síntese coletiva do movimento de apropriação conceitual pelos sujeitos.

\section{Referências}

AGUIAR, C. P. de. Processos de aprendizagem da docência com professores que ensinam matemática nos anos iniciais: a coletividade como princípio formativo. Dissertação (Mestrado). Programa de Pós-graduação em Educação em Ciências e Matemática. Universidade Federal do Paraná, 2018.

ARAUJO, E. S. Atividade orientadora de ensino: princípios e práticas para organização do ensino de matemática. Revista Paranaense de Educação Matemática, Campo Mourão, PR, v. 8, n. 15, p. 123-146, jan-jun. 2019. Disponível em:

http://rpem.unespar.edu.br/index.php/rpem/article/view/1822. DOI: https://doi.org/10.33871/22385800.2019.8.15.123-146.

ARAÚJO, N. A. de. O professor em atividade de aprendizagem de conceitos matemáticos. Tese (Doutorado). Faculdade de Educação da Universidade de São Paulo, 2015. DOI: https://doi.org/10.11606/t.48.2016.tde-19102016-144907.

BEMME, L. S. B. Como entendemos a matemática ensinada nos anos iniciais? Com a palavra os licenciandos em matemática. Dissertação (Mestrado). Universidade Federal de Santa Maria, 2015.

BRANCO, A. R. A atividade de ensino do professor de matemática do sexto ano: sentidos da prática docente. Dissertação (Mestrado). Universidade Federal de São Paulo, 2018. 
CARVALHO, R. J. da S. Investigando a apropriação dos nexos conceituais do sistema de numeração decimal no clube de matemática. Dissertação (Mestrado). Universidade Federal de Goiás, 2017.

CEDRO, W. L. O espaço de aprendizagem e a atividade de ensino: o Clube de Matemática. Dissertação (Mestrado). Faculdade de Educação: Universidade de São Paulo, 2004. DOI: https://doi.org/10.11606/d.48.2004.tde-21062005-104453.

CEDRO, W. L. O motivo e a atividade de aprendizagem do professor de Matemática: uma perspectiva histórico-cultural. Tese (Doutorado). Faculdade de Educação: Universidade de São Paulo, 2008. DOI: https://doi.org/10.11606/t.48.2008.tde-17122009-080649.

CEDRO, W. L.; MORETTI, V. D.; MORAES, S; P. G de. Desdobramentos da Atividade Orientadora de Ensino para a organização do ensino e para a investigação sobre a atividade pedagógica. Linhas críticas, Brasília, DF, v. 24, p. 431-452, 2018. DOI: https://doi.org/10.26512/lc.v24i0.21851.

COSTA, R. C. da. Materiais didáticos na atividade de ensino de matemática: significação dos artefatos mediadores por professores em formação contínua. Tese (Doutorado). Faculdade de Educação: Universidade de São Paulo, 2016. DOI: https://doi.org/10.11606/t.48.2016.tde-15082016-162237.

MORAES, S. P. G. de. Avaliação do Processo de Ensino e Aprendizagem em Matemática: contribuições da teoria histórico-cultural. Tese (Doutorado). Faculdade de Educação: Universidade de São Paulo, 2008. DOI: https://doi.org/10.11606/t.48.2008.tde-16032009-145709.

MOURA, M. O. de. A atividade de ensino como unidade formadora. Bolema, ano II, $\mathrm{n}^{\circ} 12,1996$.

MOURA, M. O. de. (Org.) A atividade pedagógica na teoria históricocultural. 2a ed. Campinas: Autores Associados, 2016.

MOURA, M. O. de. et al. A atividade Orientadora de Ensino como unidade entre ensino e aprendizagem. In: MOURA, M. O. de (org.). A atividade pedagógica na teoria histórico-cultural. $2^{\mathrm{a}}$ ed. Campinas: Autores Associados, 2016. (p. 93-125). DOI: https://doi.org/10.7213/rde.v10i29.3094.

MOURA, M. O. de; SFORNI, M. S. F.; LOPES, A. R. L.V. Objetivação do Ensino e o desenvolvimento do Modo Geral de Aprendizagem da Atividade Pedagógica. In MOURA, M. O. de (Org.). Educação escolar e pesquisa na teoria histórico-cultural. São Paulo: Edições Loyola, 2017. 
MOURA, M. O. de, ARAUJO, E. S., SERRÃO, M. I. B. Atividade Orientadora de Ensino: fundamentos. Linhas Críticas, Brasília, DF, 2018, v.24 - Ahead of print, p.411-430. DOI: https://doi.org/10.26512/lc.v24i0.19817.

NASCIMENTO, C. P.; MOURA, M. O. de. Dos princípios às ações organizadoras da atividade pedagógica. In: PEDERIVA, P. L. M. et al (org). Educar na perspectiva histórico-cultural: diálogos vigotskianos. Campinas: Mercado de Letras, 2018. (p. 53-77).

PANOSSIAN, M. L., MORETTI, V. D., SOUZA, F. D. Relações entre movimento histórico e lógico de um conceito, desenvolvimento do pensamento teórico e conteúdo escolar. In: MOURA, M. O. (org). Educação escolar e pesquisa na teoria histórico-cultural. São Paulo: Loyola, 2017. (p. 125-152).

RUBTSOV, V. A atividade de aprendizado e os problemas referentes à formação do pensamento teórico dos escolares. In: GARNIER, C. et al. Após Vygotsky e Piaget: perspectivas social e construtivista. Porto Alegre: Artes Médicas, 1996. (p. 129-137).

VIRGENS, W. P. das. Problemas desencadeadores de aprendizagem na organização do ensino: sentidos em movimento na formação de professores de matemática. Tese (Doutorado). Faculdade de Educação: Universidade de São Paulo, 2019. DOI: https://doi.org/10.11606/t.48.2019.tde-03102019-120541.

SILVA, D. S. G. A avaliação do movimento de ensinar e aprender matemática nos anos iniciais do ensino fundamental. Dissertação (Mestrado). Universidade Federal de Santa Maria, 2014. 